\title{
Molecular Cloning and Characterization of a Chitinase Gene from the Thermophilic Fungus, Thermomyces lanuginosus-RMB
}

\author{
Peramachi Palanivelu * and Lakshmi Vaishna ${ }^{\$}$ \\ * Senior Professor \& Head, Department of Molecular Microbiology, School of Biotechnology, \\ Madurai Kamaraj University,Madurai-625021, India. \\ \$Present address: Strides Arcolab Limited, Strides House, Bilekahalli, Bannerghatta Road, Bangalore- \\ 560076, India.
}

\begin{abstract}
A chitinase gene from the thermophilic fungus, Thermomyces lanuginosus was amplified from the genomic DNA of the fungus, by PCR technique. The PCR product was cloned into pXcmkn12 vector by TA cloning technique and sequenced. The gene contained five introns and six exons. The deduced protein sequence coded for 390 amino acids and exhibited very high degree of similarity to other endochitinases of mesophilic and thermophilic fungi. The highly conserved catalytic motif, DGLDIDWEYP, suggests that it belongs to family 18 chitinases.
\end{abstract}

Keywords: Thermophilic fungus, Thermomyces lanuginosus, Family 18 Chitinase, Introns

\section{Introduction}

Chitin is a linear, insoluble, homopolymer made up of $\beta, 1-4$ linked $\mathrm{N}$-acetyl glucosamine (GlcNac). It is a major component of cuticles of insects and shells of crustaceans. It also forms an important component of the cell wall of many fungal species. Thus, chitin is the second most abundant biopolymer next to cellulose. Therefore, chitin degradation and chitinases are of biotechnological importance. Chitinases degrade chitin into mainly mono and dimeric units of GlcNac. These enzymes are ubiquitous and are reported from bacteria, yeasts, higher fungi, plants and animals. In plants and animals, their role is mainly defensive.

The chitinases are classified into exo- and endochitinases based on their mode of action. Endochitinases (EC 3.2.1.14) cleave the polymer randomly whereas exochitinases (EC 3.2.1.29) catalyze progressive release of chitobiose residues from the non reducing end of the polymer. N-acetyl- $\beta$-Dglucosaminidases (EC 3.2.1.30) release GlcNac residues from chitin oligomers in an exo-fashion. However, based on their sequence and structural similarities they are classified into family 18 and family 19 glycosidases. Family 18 chitinases are structurally different from family 19 chitinases and consist of a highly conserved catalytic motif (DxxDxDWEYP) and are inhibited by allosamidin, a pseudotrisaccharide isolated from Streptomyces sp. Bacterial, fungal, animal, and some of the plant chitinases belong to family 18 glycosyl hydrolases whereas most of the plant chitinases and some bacterial chitinases belong to family 19 glycosyl hydrolases [1,2]. It is interesting to note that the family 19 chitinases have no sequence similarity to family 18 chitinases and are not inhibited by allosamidin.

Recently, chitinases have received considerable attention as they could be used in augmenting plant defense system against chitin containing pathogens such as fungi and nematodes. Fungal chitinases are found to be up to 100 times more active than the corresponding plant enzymes and effective on a much wider range of pathogens and non toxic to plants even at high concentrations [3]. Moreover they may not involve in gene silencing in transgenic plants. Therefore, fungal chitinases are considered as the best choice for production of transgenic plants against fungal pathogens.

A large number of genes encoding chitinases have been isolated and analyzed from a wide variety of fungi including yeast and filamentous fungi such as Saccharomyces cerevisiae [4], Apanocladium album [5], Candida albicans [6], Rhizopus oligosporus [7], Trichoderma harzianum [8, 9], Trichoderma reesei [10], Trichoderma atroviride [11], Thermomyces lanuginosus [12], Aspergillus nidulans [13] and Gliogladium roseum [14].

Genes encoding for chitinases have been successfully used for the production of transgenic plants to effectively control a large number of plant pathogenic fungi, which are major pathogens leading to crop loss [3, 15-18] . In the light of stringent IPRs, the gene/plasmid constructs harbouring commercially important genes such as chitinase gene are not freely available and therefore, attempts were made to clone the gene from a thermophilic fungus, which grows optimally at $50^{\circ} \mathrm{C}$. Here we report the molecular cloning and characterization of a chitinase gene from an Indian isolate of the thermophilic fungus, Thermomyces lanuginosus-RMB. Sequence data shows that the chitinase gene isolated in the present study belongs to family 18 chitinase, similar to the chitinases found in the mycoparastic fungi (Trichoderma sp.), that have been very widely used for 
production of transgenic plants. Therefore, the thermophilic fungal chitinase with broad temperature optimum and better thermostability could also be exploited to generate transgenic plants against fungal pathogens.

\section{Materials and Methods}

T. lanuginosus-RMB was obtained from Dr. Ramesh Maheshwari, Indian Institute of Science, Bangalore-560012. Restriction enzymes, dNTPs, ligase and Taq polymerase were from Bangalore Genie Pvt. Ltd., Bangalore, India. The restriction enzyme XcmI was obtained from New England Biolabs, USA. The plasmid pXcmkn12 was kindly provided by Dr. Seiichi Yasuda, Department of Microbial genetics, National Institute of Genetics, Mishima, Japan. All other chemicals used were of analytical grade obtained from Indian manufacturers.

\subsection{Growth conditions}

The fungus was grown in a modified Vogel's medium containing $2 \%$ glucose and $0.01 \%$ Vogel's trace elements stock solution [19]. The $\mathrm{pH}$ of the medium was adjusted to 6.5 with $\mathrm{KOH}$ and the medium was sterilized by autoclaving at $15 \mathrm{psi}$ for $20 \mathrm{~min}$. The mycelial inoculum was prepared by incubating the spores in $50 \mathrm{ml}$ of mannitol-asparagine medium according to Palanivelu et al. [20].containing $0.2 \%$ yeast extract in a 250 $\mathrm{ml}$ Erlenmeyer flask, at $50^{\circ} \mathrm{C}$ for $12-16 \mathrm{hr}$ on a gyratory shaker at $150 \mathrm{rpm}$. Fungal culture was raised in $100 \mathrm{ml}$ medium in $500 \mathrm{ml}$ Erlenmeyer flasks using a $3 \%$ mycelial inoculum (Cell density $\sim 10 \mathrm{mg} \mathrm{dry} \mathrm{wt} / \mathrm{ml}$ ) at $50^{\circ} \mathrm{C}$ for 12-15 hr on a gyratory shaker. The mycelium was harvested by suction filtration and washed twice with distilled water. Moisture was removed by pressing the mycelium several times between layers of blotting paper and then weighed and stored at $-20^{\circ} \mathrm{C}$.

\subsection{Isolation of genomic and plasmid DNAs}

High molecular weight genomic DNA was isolated according to the method of Basha and Palanivelu [21]. Plasmid DNAs were isolated by a modified alkaline lysis procedure published by Basha and Palanivelu [22]. The genomic and plasmid DNAs and PCR products were routinely analyzed by $0.8 \%$ agarose gel electrophoresis.

\subsection{PCR conditions for amplification of genomic DNA}

The genomic DNA was amplified by PCR technique using the forward and reverse primers ATTGGGCCATTTATGGT and TTTCTCGATGACATTGTG, respectively. The PCR reaction mixture in a total volume of $25 \mu \mathrm{l}$ contained $2.5 \mu \mathrm{l} 10 \mathrm{X}$ buffer, $1.0 \mu \mathrm{l} \mathrm{dNTP} \operatorname{mix}(10 \mathrm{mM}), 0.5 \mu \mathrm{l}$ primers $(10 \mathrm{pmoles} / \mu \mathrm{l})$, $0.5 \mu \mathrm{l}$ template DNA $(0.1 \mu \mathrm{g}), \quad 0.5 \mu \mathrm{l} \mathrm{Taq}$ polymerase (3 units $/ \mu \mathrm{l})$. After $4 \mathrm{~min}$ of initial denaturation at $94^{\circ} \mathrm{C}$, the genomic DNA was amplified with the following conditions, $94^{\circ} \mathrm{C} / 30 \mathrm{sec} ; 55^{\circ} \mathrm{C} / 60 \mathrm{sec} ; 72^{\circ} \mathrm{C} / 2 \mathrm{~min}$ for 30 cycles and the final extension was done at $72^{\circ} \mathrm{C}$ for $10 \mathrm{~min}$.

\subsection{Extraction of DNA from agarose gels, restriction digestion and ligation}

Extraction of DNA from agarose gels, restriction digestion and ligation were done according to the recommendations of the manufacturers. The ligation reaction in a total volume of $20 \mu \mathrm{l}$, contained $7 \mu \mathrm{l}$ eluted PCR product, $1 \mu \mathrm{l} \mathrm{pXcmkn} 12$ backbone, $10 \mu \mathrm{l}$ of 10X ligase buffer and $2 \mu \mathrm{l}$ of ligase. The ligation mixture was incubated at $16^{\circ} \mathrm{C}$ for $24 \mathrm{hr}$ and used to transform freshly prepared E. coli (DH5 $\alpha$ ) competent cells. The recombinant plasmids from the transformants were digested with BamHI to release the fragment. The restriction digestion reaction in a total volume of $20 \mu \mathrm{l}$, contained $10 \mu \mathrm{l}$ recombinant plasmid, $2 \mu \mathrm{l}$ 10X BSA, 2 $\mu \mathrm{l}$ of 10X BamHI buffer, $1 \mu \mathrm{l}$ of BamHI enzyme and $5 \mu \mathrm{l}$ of Milli Q water. The reaction was incubated at $37^{\circ}$ $\mathrm{C}$ for $2 \mathrm{hr}$ and analyzed in $1 \%$ agarose gels.

\subsection{Sequencing of the recombinant DNA plasmid}

The plasmid from recombinant clones containing the insert was purified by polyethylene glycol (PEG) procedure and sequenced.

\subsection{Bioinformatics analyses of chitinases sequences}

Multiple sequence alignment was done using the software TCOFFEE (advance version) available in the website www.tcoffee.org. BLAST analyses were done from the PubMed site.

\section{Results and Discussion}

\subsection{Isolation of genomic DNA from Thermomyces lanuginosus-RMB}


Fig. 1 shows the agarose gel electrophoresis of genomic DNA isolated from the fungus. It showed a single band of high molecular weight. The DNA concentrations were quantified spectrophotometrically. The final genomic DNA concentration was adjusted to $1 \mu \mathrm{g} / \mu$ l with $1 \mathrm{X}$ TE buffer ( $\mathrm{pH} 8.0$ ).

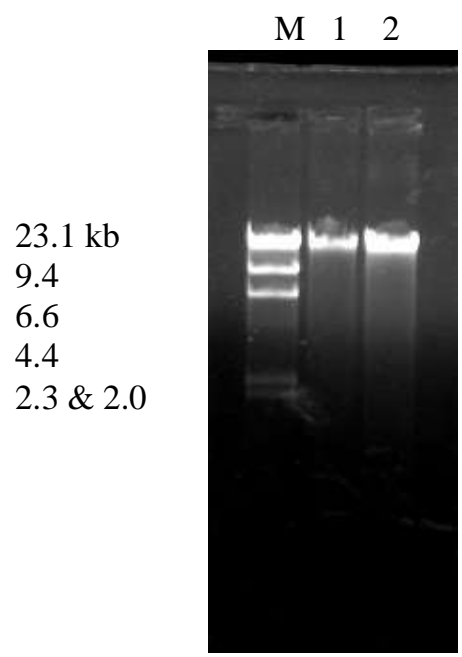

Fig: 1. Agarose gel electrophoresis of genomic DNA from T. lanuginosus Lane M, DNA Marker ( $\lambda$ DNA digested with HindIII)

Lane 1, $5 \mu$ l genomic DNA

Lane 2, $10 \mu$ l genomic DNA

\subsection{Amplification of the genomic DNA}

The genomic DNA was amplified according to the conditions described in the Materials and Methods. The amplified PCR product was analyzed by agarose gel electrophoresis (Fig. 2).

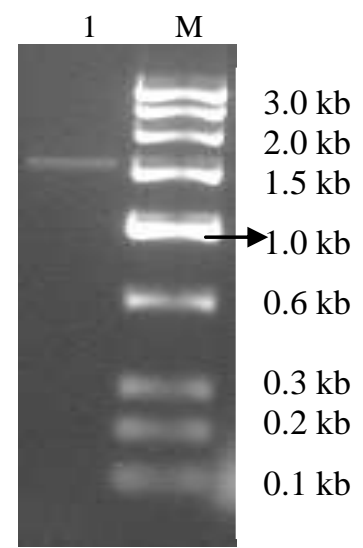

Fig: 2. Agarose gel electrophoresis of PCR amplified product

Lane 1, PCR amplified product

Lane M, Low range DNA ruler

It showed a single band suggesting that the PCR conditions were optimal and no non-specific amplifications were seen. The amplicon size was about $1.7 \mathrm{~kb}$ in length.

\subsection{Molecular cloning of the PCR product in pXcmkn12 vector}

The plasmid pXcmkn12 was used to transform E. coli $\mathrm{DH} 5 \alpha$ and the plasmid was isolated from a transformed colony according to the method published by Basha and Palanivelu [22] and purified by using Bangalore Genie gel extraction kit. The eluted plasmid was cleaved with the restriction enzyme XcmI and the backbone was again purified by using Bangalore Genie gel extraction kit. The amplified product was also purified from the gel by using the above kit. The eluted fragments were found to be homogenous (Fig. 3). 


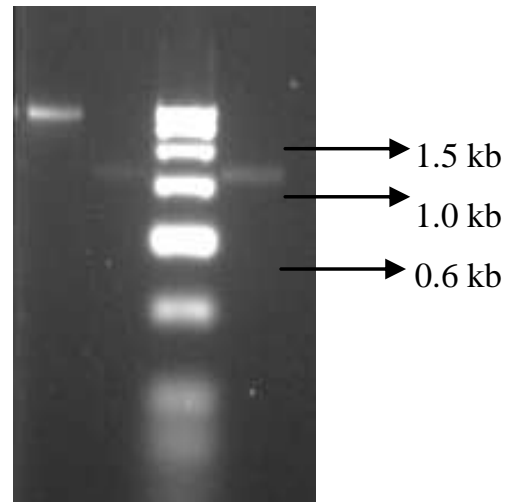

Fig: 3. Agarose gel electrophoresis of eluted pXcmkn12 backbone and the PCR amplified product

Lane $1, \mathrm{pXcmkn} 12$

Lanes 2 \& 3, PCR amplified product

Lane $\mathrm{M}$, Low range DNA ruler

The pXcmkn12 plasmid backbone and the PCR product were subjected to ligation according to manufacturer's recommendation, for $16 \mathrm{hr}$ at $16^{\circ} \mathrm{C}$. The ligated mixture was used to transform E. coli DH5 $\alpha$ competent cells. The ampicillin resistant colonies were patched again in LB plates containing $100 \mu \mathrm{g} / \mathrm{ml}$ ampicillin and then selected for further analysis. The plasmids were isolated from the recombinant clones as reported earlier [22] and were analyzed by agarose gel electrophoresis. A mobility shift was observed from the plasmids isolated from the recombinant clones. The transformants were further confirmed by digestion with BamHI. (The BamHI digestion releases any insert cloned into $\mathrm{pXcmkn12).} \mathrm{The} \mathrm{recombinant} \mathrm{plasmids} \mathrm{released}$ an expected $1.7 \mathrm{~kb}$ insert which was named pXchi-PPLV2 (Fig. 4).

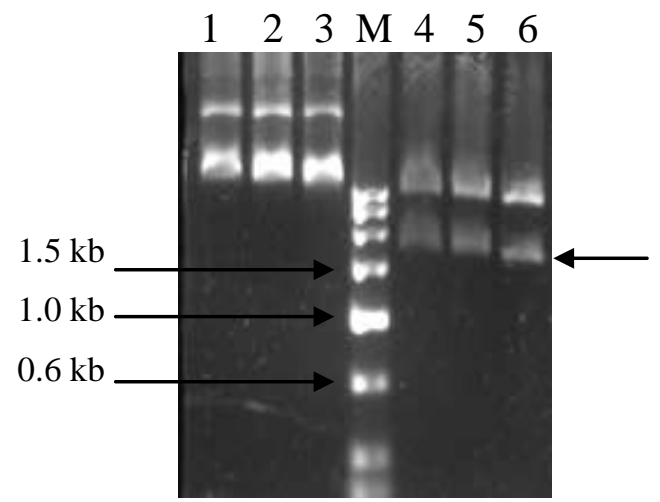

Fig: 4. Agarose gel electrophoresis of recombinant plasmids before and after Bam HI digestion Lanes 1,2 \& 3, Plasmids from recombinant clones

Lane $\mathrm{M}$, Low range DNA ruler

Lanes 4, 5 \& 6, Bam HI digested recombinant plasmids

(The insert released, is indicated by the arrow mark).

\subsection{Sequencing and sequence analysis}

The PEG purified recombinant plasmid DNA from pXchi-PPLV2 was sequenced. The sequence using the forward primer ( 807 nucleotides) and the reverse primer sequence ( 823 nucleotides) were assembled to obtain the complete sequence (1630 nucleotides). The complete genomic sequence is shown in Fig. 5. (The complete genomic DNA sequence is deposited in the Genbank; Genbank accession No. JQ801444). 
Molecular Cloning And Characterization Of A Chitinase Gene From The Thermophilic Fungus,

\begin{abstract}
ATTGGGCCATTTATGGTCGCAACCATAATCCCCAAGACCTGCCTGCCGAG AAACTAACGCATATTCTATACGCCTTTGCCAATGTGAGGCCGGATAGTGG TGAAGTgtagatatctctattccetgaatatcgaaagtacatactgagaaatactgcgttagGTACCTTA CCGACACCTGGTCGGACACGGACAAGCATTACCCGAGTGACTCCTGGAAT GACACCGGGACCAACGTCTACGGCTGCATCAAACAACTCTTTCTCCTCAAG AAGCGGCATCGTAAACTCAAGGTTCTGCTGTCTATTGGCGGGTGGACGTAT TCATCAAACCTTGCCCAGCCAGCCAGCACCGAGGCCGGACGCGAGACCTTT GCCCGAACCGCCACGAGATTGGTGCTAGATCTAGGGCTGGACGGTCTCGAT ATCGACTGGGAATACCCACAAGgtctgttttgcggaccettggtgattatttcttgctgacaggttcttt tcgtctagACGATAACCAGGCGCGTGACTTTGTGGCTCTGCTGCGCAAATGCCG GGAGgtgcgttcgtcgttaccetggggettttttttttttttttttttttttttttttttttttttnccagnaagctctaatggc attgcagCATTTGGATTACCCCGCGGGCCCAAATCGGAGGTTCCTCCTGACCAT TGCCTGCCCAGCTGgtaggtttcgtetgcacataggagcttactgatattgaccaatctcagGTCCTAA CAACTTTACCAAGCTTCGCCTGCCAAAAATGACACCGTACTTGGACTTTTAA ATCTAATGGGCTACGACTATGCTGgtaagcttttgccaagaaagacttttgccatcacactgacagt cgcagGCTCTTGGGACCAACTCGCCGGCCACCAGGCCAACATTTTCCCCTCTTC AACCAACCCTGCCTCTACGCCATTCTCAACCGATGCAGCCCTACGACACTAC ATCAGTGTCAGCGGCGTGCCATCGTCGAAAATGGTATTGGGCATGCCGCTCT ACGGGCGCGCATTCCAAAACACCAATGGCCCCGGAACGCCGTTCAGTGGTG TGGGTGAGGGAAGCTGGGAGCAAGGCGTGTGGGACTATAAAGCTTTGCCCC GGCCTGGTGCTACGGAGCACGTTGATCCTAACATCGGGGCGTCGTGGTCGTA CGATCCCCAGACCAGAACTATGGTCACCTATGATAACGTTGCCGTTGCCGAG ATCAAGGCCAACTTCGTCCGCGGAGCCGGCCTTGGTGGAGGTATGTGGTGGG AGAGTAGTGCTGACCGAGGCGGGAAGACGGCCAATAAAGCTGATGGCAGTC TCATCGGAACCTTTGTGGACGGATTGGGTGGCGTTTTCGCATTGGATCAGTCG CCTAACAACCTTGATTATCCGGAGAGCAAGTATGACAATCTCCGGGCTGGCTT CCCGGGAGAGTGAATCTGAACTCGACGGTGGCACATGGGTATATGCACCGTTC GCACACACGTACGAGTACACAATTTACGACTACAGCATTAGGATAGAGAATCA CAATGTCATCGAGAAAA (Primer sequence- reverse complementary)
\end{abstract}

Fig: 5. Complete nucleotide sequence of pXchi-PPLV2

Total sequence obtained was 1630 nucleotides including the primer sequences. Intron sequences are in lower case and are underlined.

The forward and reverse primer sequences are in italics. The stop codon TAG is underlined. It contained 5 short introns and 6 exons of different sizes (Table 1).

Table: 1. Introns and their sizes of the chitinase gene from $T$. lanuginosus

\begin{tabular}{|l|l|}
\hline Intron No. & Size (bp) \\
\hline Intron 1 & 56 \\
\hline Intron 2 & 56 \\
\hline Intron 3 & 88 \\
\hline Intron 4 & 48 \\
\hline Intron 5 & 48 \\
\hline
\end{tabular}

The introns showed characteristic borders viz., GT-AG. Blaiseau and Lafay [5] reported three introns of sizes 55, 53 and $49 \mathrm{bp}$ in the genomic sequence of the chitinase gene from the filamentous fungus, Aphanocladium album. These introns mapped close together near the $\mathrm{N}$ terminus. Klemsdal et al. [11] have found only one intron in the 1637 fragment of the genomic DNA fragment harbouring a novel chitinase gene (ech30) from $T$. atroviride. The size of the introns was $53 \mathrm{bp}$ and was located within the region encoding the active site. Gan et al. [14] have reported a 1746 bp long ORF of the chitinase gene of Gliogladium roseum which was interrupted by three short introns ( $64 \mathrm{bp}, 58 \mathrm{bp}$ and $62 \mathrm{bp}$ in length), respectively at the N-terminal part of the protein. In chitinase gene of Thermomyces lanuginosus-RMB also, most of the introns were associated with the $\mathrm{N}$ terminal part of the protein. Less number of introns in the mesophilic fungal chitinase genes suggests that some of the introns would have been lost during evolution.

The introns from the genomic sequence were deleted and the intronless sequence was converted into mRNA sequence. The stop codon and the poly-A signal site are marked (Fig. 6). 
Molecular Cloning And Characterization Of A Chitinase Gene From The Thermophilic Fungus,

ATTGGGCCATTTATGGTCGCAACCAUAAUCCCCAAGACCUGCCUGCCGAGAAACUAACGCAUAUU CUAUACGCCUUUGCCAAUGUGAGGCCGGAUAGUGGUGAAGUGUACCUUACCGACACCUGGUCG GACACGGACAAGCAUUACCCGAGUGACUCCUGGAAUGACACCGGGACCAACGUCUACGGCUGCA UCAAACAACUCUUUCUCCUCAAGAAGCGGCAUCGUAAACUCAAGGUUCUGCUGUCUAUUGGCG GGUGGACGUAUUCAUCAAACCUUGCCCAGCCAGCCAGCACCGAGGCCGGACGCGAGACCUUUGC CCGAACCGCCACGAGAUUGGUGCUAGAUCUAGGGCUGGACGGUCUCGAUAUCGACUGGGAAUA CCCACAAGACGAUAACCAGGCGCGUGACUUUGUGGCUCUGCUGCGCAAAUGCCGGGAGCAUUU GGAUUACCCCGCGGGCCCAAAUCGGAGGUUCCUCCUGACCAUUGCCUGCCCAGCUGGUCCUAAC AACUUUACCAAGCUUCGCCUGCCAAAAAUGACACCGUACUUGGACUUUUACAAUCUAAUGGGC UACGACUAUGCUGGCUCUUGGGACCAACUCGCCGGCCACCAGGCCAACAUUUUCCCCUCUUCAA CCAACCCUGCCUCUACGCCAUUCUCAACCGAUGCAGCCCUACGACACUACAUCAGUGUCAGCGG CGUGCCAUCGUCGAAAAUGGUAUUGGGCAUGCCGCUCUACGGGCGCGCAUUCCAAAACACCAA UGGCCCCGGAACGCCGUUCAGUGGUGUGGGUGAGGGAAGCUGGGAGCAAGGCGUGUGGGACUA UAAAGCUUUGCCCCGGCCUGGUGCUACGGAGCACGUUGAUCCUAACAUCGGGGCGUCGUGGUC GUACGAUCCCCAGACCAGAACUAUGGUCACCUAUGAUAACGUUGCCGUUGCCGAGAUCAAGGC CAACUUCGUCCGCGGAGCCGGCCUUGGUGGAGGUAUGUGGUGGGAGAGUAGUGCUGACCGAGG CGGGAAGACGGCCAAUAAAGCUGAUGGCAGUCUCAUCGGAACCUUUGUGGACGGAUUGGGUGG CGUUUUCGCAUUGGAUCAGUCGCCUAACAACCUUGAUUAUCCGGAGAGCAAGUAUGACAAUCU CCGGGCUGGCUUCCCGGGAGAGUGAAUCUGAACUCGACGGUGGCACAUGGGUAUAUGCACCGU UCGCACACACGUACGAGUACACAAUUUACGACUACAGCAUUAGGAUAGAGAAUCACAAUGTCAT CGAGAAAA

Fig: 6. mRNA sequence of the chitinase after deletion of the introns

The stop codon and poly (A) signal sequence are underlined.

The forward and reverse primer sequences are indicated in italics.

The first amino acid $\mathrm{W}$, starts from $\underline{U G G}$ of the forward primer (underlined

The mRNA sequence was translated using ExPASy tool and found it was almost identical (98\%) to the original sequence published by Guo and Li [12] by cDNA cloning strategy. However, the chitinase from Thermomyces lanuginosus-RMB showed 5 amino acid changes from the Chinese isolate (indicated in brackets) (Fig. 7).

WAIYGRNHNPQDLPAEKLTHILYAFANVRPDSGEVYLTDTWSDTDKHYPSDSWNDTGTNV YGCIKQLFLLKKRHRKLKVLLSIGGWTYSSNL*(F)AQPASTEAGRETFARTATRLVLDLGLDG LDIDWEYPQDDNQARDFVALLRKCREHLDYP*(A)AGPNRRFLLTIACPAGPNNFTKLRLPK*(E) MTPYLDFYNLMG*(A)YDY*(N)AGSWDQLAGHQANIFPSSTNPASTPFSTDAALRHYISVSGVPS SKMVLGMPLYGRAFQNTNGPGTPFSGVGEGSWEQGVWDYKALPRPGATEHVDPNIGASWS YDQTRTMVTYDNVAVAEIKANFVRGAGLGGGMWWESSADRGGKTANKADGSLIGTFVDG LGVFALDQSPNNLDYPESKYDNLRAGFPGE

Fig: 7. Deduced protein sequence of the chitinase gene from $T$. lanuginosus-RMB

*Amino acids which are different from the Chinese isolate are given in brackets

These changes may be due to variation in the strains. As the chitinase gene from the Chinese isolate of Thermomyces lanuginosus was cloned and sequenced by cDNA cloning method [12], no intron and exon data are available for comparison.

\subsection{Bioinformatics analyses of the chitinase sequences}

The nucleotide sequence and the translated protein sequence were analyzed by BLAST. The Blast(n) results showed maximum score (699) with chitinase sequence of the Thermomyces lanuginosus as expected. Interestingly, an endochitinase from Thermoascus auranticus and Class $\mathrm{V}$ chitinases from Taloromyces stipitatus and Penicillium marneffei had high scores of 588, 570 and 563, respectively. The Blast(p) analysis gave maximum identity (100\%) with chitinase mRNA from Thermomyces lanuginosus (Chinese isolate), followed by endochitinases of Chaetomium globosum (90\% identity) and Penicillium chrysogenum (87\% identity) (data not shown).

Trichoderma preparations from T. harzianum or T. atroviride are commonly used as bio-control agents against many plant pathogens. Moreover, chitinase gene of $T$. harzianum has been found to be very effective in transgenic plants against many fungal pathogens. Therefore, the chitinases of these two organisms were analyzed for similarity/identity by ClustalW with the chitinase sequences from $T$. lanuginosus. Multiple sequence analysis of the thermophilic fungal chitinases with $T$. harzianum and $T$. atroviride chitinases showed the conserved catalytic blocks typical of family 18 chitinases (Marked) (Fig. 8). T. lanuginosus-RMB sequence 
showed very high homology with the T. harzianum and T. atroviride chitinases. The truncated T. lanuginosusRMB sequence covers from $56^{\text {th }}$ amino acid and up to the last $\mathrm{C}$ - terminal amino acid of the original sequence [12]. Interestingly the catalytic region is completely conserved confirming the chitinase from T. lanuginosusRMB belongs to family 18 endochitinase type and hence may be effectively used for production of transgenic plants to protect crop plants from fungal pathogens. Further experiments are in progress.

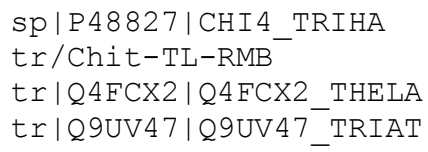

sp|P48827|CHI4 TRIHA tr/Chit-TL-RMB tr |Q4FCX2 | Q4FCX2 THELA tr|Q9UV4 7 |Q9UV47_TRIAT

sp|P48827|CHI4 TRIHA

tr/Chit-TL-RMB

tr|Q4FCX2 | Q4FCX2 THELA tr| Q9UV4 7 | Q9UV 47 TRIAT

sp |P 48827|CHI4_TRIHA tr/Chit-TL-RMB tr|Q4FCX2 | Q4FCX2 THELA tr|Q9UV4 7 | Q9UV 47-TRIAT

sp|P48827|CHI4_TRIHA tr/Chit-TL-RMB tr|Q4FCX2 | Q4FCX2 THELA tr|Q9UV4 7 | Q9UV 47_TRIAT

sp|P48827|CHI4 TRIHA tr/Chit-TL-RMB tr|Q4FCX2 | Q4FCX2 THELA tr|Q9UV47|Q9UV47_TRIAT

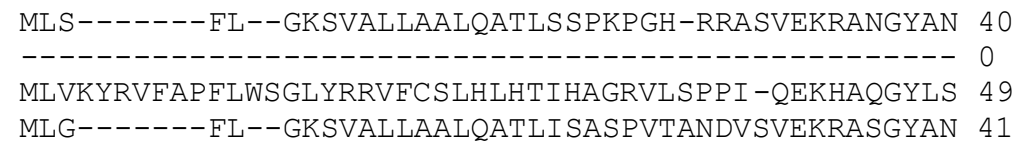

SVYFTNWGIYDRNFQPADLVASDVTHVIYSFMNLQAD-GTVISGDTYADY 89 ------WAIYGRNHNPQDLPAEKLTHILYAFANVRPDSGEVYLTDTWSDT 44 VQYFVNWAIYGRNHNPQDLPAEKLTHILYAFANVRPDSGEVYLTDTWSDT 99 AVYFTNWGIYGRNFQPQNLVASDITHVIYSFMNFQAD-GTVVSGDAYADY 90

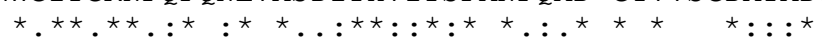

EKHYADDSWNDVGTNAYGCVKQLFKVKKANRGLKVLLSIGGWTWSTN-FP 138 DKHYPSDSWNDTGTNVYGCIKQLFLLKKRHRKLKVILSIGGWTYSSNLFA 94 DKHYPSDSWNDTGTNVYGCI KQLFLLKKRHRKLKVLLSIGGWTYSSN-FA 148 QKHYDDDSWNDVGNNAYGCVKQLFKLKKANRNLKVMLSIGGWTWSTN-FP 139

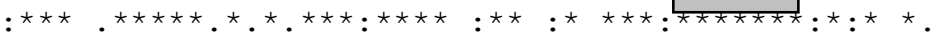

SAASTDANRKNFAKTA ITFMKDWGF DGID IDWEYAADATQASNMILLLKE 188 QPASTEAGRETFARTATRLVLDLGLDGLD IDWEYAQDDNQARDFVALLRK 144 QPASTEAGRETFARTATRLVLDLGLDGLD IDWEYAQD DNQARDFVALLRK 198 SAASTDANRKNFAKTA ITFMKDWGF DGIDVDWEYAADDTQATNMVLLLKE 189

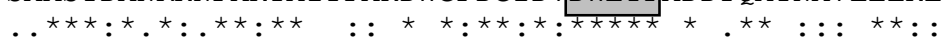

VRSQRDAYAAQYAPGYHFLLTIAAPAGKDNYSKLRLA-DLGQVLDYINLM 237 CREHLDYPAA--GPNRRFLLTIACPAGPNNFTKLRLPKEMTPYLDFYNLM 192 CREHLDY-AA--GPNRRFLLTIACPAGPNNFTKLRLP-EMTPYLDFYNLM 244 IRSQLDAYAAQYAPGYHFLLSIAAPAGPE HYSFLHMS -DLGQVLDYVNLM 238

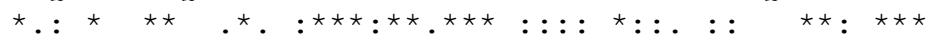

-AYDY-AGSFSPLTGHDANLFNNPSNPNATPFNTDSAVKDYIN-GGVPAN 284 GAYDYNAGSWDQLAGHQANIFPSSTNPASTPFSTDAALRHYISVSGVPSS 242 -AYDN-AGSWDQLAGHQANIFPSSTNPASTPFSTDAALRHYISVSGVPSS 292 -AYDY-AGSWSSYSGHDANLFANPSNPNSSPYNTDQAIKDYIK-GGVPAS 285

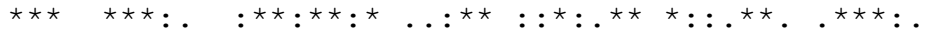

KIVLGMPIYGRSFQNTAGIGQTYNGVGSGSWEAGIWDYKALPKAGATVQY 334 KMVLGMPLYGRAFQNTNGPGTPFSGVGEGSWEQGVWDYKAL PRPGATEHV 292 KMVLGMPLYGRAFQNTNGPGTPFSGVGEGSWEQGVWDYKALPRPGATEHV 342 KIVLGMPIYGRAFESTGGIGQTYSGIGSGSWENGIWDYKVLPKAGATVQY 335

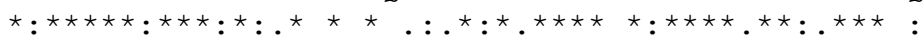

DSVAKGYYSYNSATKELISFDTPDMINTKVAYLKSLGLGGSMFWEASADK 384 DPNIGASWSYD-QTRTMVTYDNVAVAEIKANFVRGAGLGGGMWWESSADR 341 DPNIGASWSYDPQTRTMVTYDNVAVAEIKANFVRGAGLGGGMWWESSADR 392 DSVAQAYYSYDPSSKELISFDTPDMINTKVSYLKNLGLGGSMFWEASADK 385

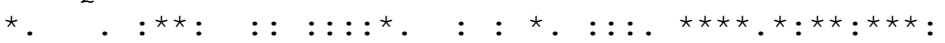

KGA------DSVIGTSHRALG---GLDTTQNLLSYPNSKYDNIKNGL--N 423 GGKTANKADGSLIGTFVDGLGV-FALDQSPNNLDYPESKYDNLRAGFPGE 390 GGKTANKADGSLIGTFVDGLGGVFALDQS PNNLDYPESKYDNLRAGFPGE 442 TGS------DSLIGTSHRALG---SLDSTQNLLSYPNS-----------Q 415

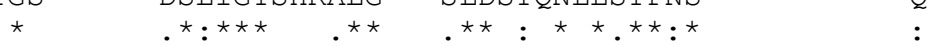

Fig: 8. ClustalW analysis of thermophilic fungal chitinases with Trichoderma chitinases

The highly conserved catalytic block in family 18 chitinases is highlighted.

No change was observed in the conserved blocks between the original sequence (Chinese isolate) and from $T$. lanuginosus-RMB (Indian isolate, present communication). 


\section{Conclusion}

A chitinase gene is cloned and sequenced along with its introns and exons for the first time from the genomic DNA of the thermophilic fungus, Thermomyces lanuginosus RMB. The deduced protein sequence is found to be very similar to other mycoparasitic fungal chitinase sequences. The catalytic motif DGLDIDWEYP is highly conserved in the thermophilic fungal chitinase. Therefore, this gene could be used for the production of transgenic plants against fungal pathogens.

\section{Acknowledgements}

The first author wishes to thank the University Grants Commission (UGC), New Delhi, for financial assistance under Centre for Potential in the Subject of Genomic Sciences and also under UGC (MRP). The second author was supported as a project assistant under UGC's Centre for Potential in the Subject of Genomic Sciences. 


\section{References}

[1] B Henrissat and Bairoch A, New families in the classification of glycosyl hydrolases based on amino acid sequence similarities, Biochemical Journal, 293, 1993, 781-788.

[2] B Henrissat B, Classification of chitinases modules, EXS 87, 1999, 137-156.

[3] M Lorito, Woo S L, Fernandez I G, Colucci G, Harman G E, Pintor-toro J A, Filippone E, Muccifora S, Lawrence C B, Zoina A, Tuzun S and Scala F, Genes from mycoparasitic fungi as a source for improving plant resistance to fungal pathogens, Proceedings of the National Academy of Sciences (USA), 95, 1998, 7860-7865.

[4] M.J. Kuranda and Robbins P W, Chitinase is required for cell separation during growth of Saccharomyces cerevisiae, Journal of Biological Chemistry, 266, 1991, 19758-19767.

[5] L.P. Blaiseau, and Lafay F J, Primary structure of a chitinase-encoding gene (chil) from the filamentous fungus Aphanocladium album: similarity to bacterial chitinases, Gene, 120, 1992, 243-248.

[6] K.J. McCerath, Specht C A and Robbins P W, Molecular cloning and characterization of chitinase from Candida albicans, Proceedings of the National Academy of Sciences (USA), 92, 1995, 2544-2458.

[7] N. Takaya, Yamazaki D, Horiuchi, H, Ohta A and Takagi M, Intracellular chitinase gene from Rhizopus oligosporus: molecular cloning and characterization, Microbiology, 144, 1998, 2647-2654.

[8] A. Viterbo, Haran S, Friesem D, Ramot O and Chet I, Antifungal activity of a novel endochitinase gene (chit36) from Trichoderma harzianum Rifai TM, FEMS Microbiology Letters, 200, 2001, 169-174.

[9] C. Carsolia, Gutterrez A, Jimenez B, Montagu M V and Estrella A H, Characterization of ech-42, a Trichoderma harizianum encochitinase gene expressed during mycoparasitism, Proceedings of the National Academy of Sciences (USA), 91, 1994, 1090310907.

[10] V. Seidl, Huemer B, Seiboth B and Kubicek C P, A complete survey of Trichoderma chitinases reveals three distinct subgroups of family 18 chitinases, FEBS Journal, 272, 2005, 5923-5939.

[11] S.S. Klemsdal, Clarke J L, Hoell I A, Eijsink, V G H and Brurberg M B, Molecular cloning, characterization, and expression studies of a novel chitinase gene (ech30) from the mycoparasite Trichoderma atroviride strain P1, FEMS Microbiology Letters, 256, 2006, 282-289.

[12] R.F. Guo and Li D C, Molecular cloning and expression of a chitinases gene from the thermophilic fungus Thermomyces lanuginosus, Acta Microbiology Sin 46, 2006, 99-103 (in Chinese).

[13] N. Nakaya, Yamazaki D, Horiuchi H, Ohta A and Takagi M, Cloning and characterization of a chitinase encoding gene (chiA) from Aspergillus nidulans, disruption of which decreases germination frequency and hyphal growth, Bioscience Biotechnology Biochemistry, 62, 1998, 60-65.

[14] Z. Gan, Yang J, Tao N, Yu Z and Zhang K, Cloning and Expression Analysis of a Chitinase Gene Crchilfrom the Mycoparasitic Fungus Clonostachys rosea (syn. Gliocladium roseum), Journal of Microbiology, 45, 2007, 422-430.

[15] J. P. Bolar, Norelli J L, Wong K W, Hayes C K, Harman G E \& Aldwinckle H S, Expression of endochitinase from Trichoderma harzianum in transgenic apple increases resistance to apple scab and reduces vigour, Phytopathology, 90, 2000, $72-77$.

[16] C Emani, Garcia, J M, Lopata-Finch, E, Pozo, M J, Uribe P, Kim D J, Sunilkumar, G, Cook D R, Kenerley, C M and Rathore K S, Enhanced fungal resistance in transgenic cotton expressing an endochitinase gene from Trichoderma virens, Plant Biotechnology Journal, 1, 2003, 321-336.

[17] R. Baranski, Klocke E and Nothnagel T, Chitinase CHIT36 from Trichoderma harzianum Enhances Resistance of Transgenic Carrot to Fungal Pathogens, Journal of Phytopathology, 156, 2008, 513-521.

[18] G.V.S Saiprasad, Mythili, J B, Anand, L Suneetha C, Rashmi, H J, Naveena C and Ganesan G, Development of Trichoderma harzianum endochitinase gene construct conferring antifungal activity in transgenic tobacco, Indian journal of Biotechnology, 8 , 2009, 199-206.

[19] P. Palanivelu, Analytical Biochemistry and Separation Techniques, IV edition, (21 $1^{\text {st }}$ Century Publication, Palkalai Nagar, Madurai21, India, 2009).

[20] P. Palanivelu, Balasubramaniyam P V and Maheshwari R, Coinduction of sucrose transport and invertase activities in the thermophilic fungus, Thermomyces lanuginosus, Archives of Microbiology, 139, 1984, 44-47.

[21] S.Y. Basha and Palanivelu P, Two simple non-enzymatic procedures to isolate high molecular weight DNA from fungi, Current Science, 68, 1995, 587-588.

[22] S. Y. Basha and Palanivelu P, A modified alkaline lysis procedure for isolation of plasmids from E. coli, Current Science, 66, 1994, 335-336. 